\title{
Pattern of Partial Edentulism and Its Relation to Age, Gender, Causes of Teeth Loss in Jazan Population
}

\author{
Mohammed M. Al Moaleem ${ }^{1,}$, Dawood M. Somaili ${ }^{2}$, Tayeb A. Ageeli ${ }^{2}$, Sultan M. Namis ${ }^{2}$, \\ Abdulaziz H. Mobarki ${ }^{2}$, Mohamed Sobhy Mohamed ${ }^{1}$, Jameel A Saib ${ }^{1}$, Khurshid A. Matto ${ }^{1}$ \\ ${ }^{1}$ Department of Prosthodontics, College of Dentistry, Jazan University, Jazan, KSA \\ ${ }^{2}$ Department of Internes, College of Dentistry, Jazan University, Jazan, KSA
}

Email address:

Drmoaleem2014@gmail.com (M. M. A. Moaleem)

${ }^{*}$ Corresponding author

\section{To cite this article:}

Mohammed M. Al Moaleem, Dawood M. Somaili, Tayeb A. Ageeli, Sultan M. Namis, Abdulaziz H. Mobarki, Mohamed M. Sobhy Mohamed, Jameel A Saib, Khurshid A. Matto. Pattern of Partial Edentulism and Its Relation to Age, Gender, Causes of Teeth Loss in Jazan Population. American Journal of Health Research. Vol. 4, No. 5, 2016, pp. 121-126. doi: 10.11648/j.ajhr.20160405.12

Received: July 27, 2016; Accepted: August 4, 2016; Published: August 25, 2016

\begin{abstract}
Introduction: Statistic distribution of Kennedy's classifications and tooth loss among general population are important reasons to assess the dentures needs and impact of preventive dentistry in any society. Aim: To determine the frequency and pattern of Kennedys classification among Jazan population in relation to different age group, gender, sites and causes of tooth loss. Material and methods: The data was collected between May 2014 and May 2015 from patients who required removable partial dentures. Clinical intra-oral and radiographic examinations were done, then the data were registered and the Kennedy classes and causes of teeth loss were recorded. The number of subjects participated were 339 male and 240 female. They were divided into five groups, 20-29, 30-39, 40-49, 50-59 and $\geq 60$ years respectively. All relevant data were entered into SPSS program and analyzed accordingly using Fisher exact test. Results: The highest number of patients among males and females were in age group of 50-59 year. Kennedy's class III was the highest among all age groups. In males, class III Kennedy classification was the highest in both arches, while class I was the highest in female. Periodontal disease was the major cause of tooth loss in both genders, followed by dental caries. A combination of both causes was founded in less than $10 \%$ of subjects. There were significant differences between all groups. The obtained $\mathrm{P}$ values were statistically significant $(\mathrm{p}<.000)$. Conclusion: Kennedys Class III had highest frequency in males in all age groups and in both arches whereas in females, Kennedys class I was the highest. Periodontal disease was the most common cause of tooth loss in all genders followed by dental caries.
\end{abstract}

Keywords: Partial Edentulism, Dental Arch, Age, Sex, Tooth Extraction, Saudi Arabia

\section{Introduction}

In any population tooth loss is an overall indicator of the oral health [1]. Dental caries, periodontitis, orthodontics, trauma, prosthetic treatments and combinations of these, have been cited as some of the common reasons for extraction of teeth in the available literatures Various surveys on the causes of tooth loss in different countries have been conducted and have produced some controversy regarding whether periodontal and /or caries diseases are the main reasons for tooth loss [2-4].

Different methods of partial edentulism classification, on the basis of potential combinations of teeth to ridges, have been reported in the textbook [5]. At present, Kennedy's classification is the most widely accepted and used because of its simplicity, ease of application to all partially dentulous situations, immediate visualization of the type of partially edentulous arch being considered and differentiation between tooth-borne and tooth-tissue-borne partial edentulism [6]. Using this classification a tremendous number of possible semi-edentulous combinations have been reduced to four main and simple groups namely Class I, Class II, Class III and Class IV [7].

Assessment of tooth mortality information in different 
areas of the world is essential for evaluating the adequacy of dental care and preventive oral health programs [8]. The pattern of tooth loss has been evaluated in different populations in many parts of the countries [9-10]. Higher prevalence of edentulism was reported in males than in females, in a survey conducted by Hoover and McDermount [11]. While Marcus et al concluded that the prevalence of edentulism had no relationship with gender [12]. Periodic reviews of the trends in the incidence of the various classes of removable partial dentures are necessary to serve as teaching guidelines [13].

For effective allocation of available dental resources, it is necessary to understand the relative contributions of the two major oral diseases (dental caries and periodontal disease) to tooth loss. There is limited published dental literature available on epidemiological surveys investigating the reasons of tooth loss and pattern of edentulism amongst Saudi Arabian population [14-19-20]. So the purpose of this study was to determine the pattern of the partial edentulism (based on Kennedy's classification) and its relationship with certain variables such as age group, gender, arch and teeth loss causes, amongst patients examined at College of Dentistry, Jazan University, Saudi Arabia.

\section{Subject and Methods}

This cross-sectional study was approved by the Research Committee at the Faculty of Dentistry in Jazan University. The study was conducted in patient reported to outpatient section of the college. The data collections were carried out during the period of May 2014 - May 2015 for patients requiring removable partial dentures. The subject in this study was consisted of 579 patients (339 male and 240 females). All patients seeking for replacement of missing teeth were included in this study. All the patients attended to the college clinics were surveyed and the cases for this study are selected according to the certain criteria's. The inclusion criteria consisted of patients from both genders, above the age of 20 years, having partially edentulous areas in either or both arches. The Kennedys modification areas were not included to avoid the complexity. Completely edentulous patients and those with missing third molars in both arches were excluded from the study.

Selected students were involved for data collections after short period training. The examinations included both radiographic and intra-oral examinations by screening the patient in the dental chair using diagnostic kit. The examinations were done to determine the incidence of Kennedy's classification in relation to area of missing teeth (arch), causes of teeth loss, among different age groups and gender. The radiograph used in this study was a panoramic digital radiography device (Tomography X-ray System Model Pax-Flex 3D).

The selected subjects were divided into five groups, according to the age, 20-29, 30-39, 40-49, 50-59 and equal or above 60 years respectively. The clinical examination of both dental arches of each patient was carried out after written consent signatures by every patient. All relevant data related to partial edentulism was recorded in a self-designed proforma.

A tooth was classified as requiring extraction due to dental caries when caries had destroyed the crown so that it cannot be restored, if there were septic roots, or carious exposure of the pulp. A tooth was regarded as requiring extraction due to periodontal disease if it tended to satisfy the score eight criteria of Russell's PI index (Russell, 1956), namely the presence of considerable mobility according to the Miller Mobility Index Miller, 195) [21].

The clinical data were summarized, frequencies and percentages as appropriate. Association with age, gender and tooth loss causes was tested with Chi-Square (Fisher exact test). The values of $\mathrm{P}$ of $<0.05$ were considered as significant. Statistical analyses were performed using the Statistical Package for Social Sciences (SPSS).

\section{Results}

It is obvious from table $1 \& 2$ that the highest number of patients was in group 50-59 years in both arches. Class III Kennedy classification was the most prevalent among all age groups; $35.1 \%$ of Class III were in 30-39 age group regarding maxillary arch and $43.1 \%$ in 50-59 age group regarding mandibular arch (table 1 and 2). In the maxillary arch, 23.8\% of Class I cases were in age group 20-29 and it was $28.6 \%$ in $>60$ age group. While in mandibular arch $43.3 \%$ of Class I cases were in age group 20-29 and $30.0 \%$ in $40-49$ years age group. Class II cases were highest in age groups 20-29 regarding maxillary arch and in 50-59 age group regarding mandibular arch. Class IV was the highest in group 50-59 in both arches. These results were statistically significant at $\mathrm{P}>$ 0.001 .

The highest frequency and percentage of Kennedy class III was in males for both arches (maxillary 80.5\% and mandibular 75.2\%). While among females, the most frequent was Kennedy's class I for both arches. Kennedy class IV was the lowest for both arches in both genders (Table 3). These results were statistically significant at $\mathrm{P}>0.001$.

Periodontal disease was the most common cause of tooth loss in both arches; it was the most frequent cause for Class III in maxillary arch $(65.9 \%)$ and in mandibular arch (74.3\%), as shown in table $4 \& 5$. While dental caries was responsible for $80 \%$ of class I in mandibular arch and $57 \%$ in maxillary arch. The most frequent cause of tooth loss in Class VI was periodontal diseases in maxilla while most cases of Class IV in the mandibular arch had unknown causes of tooth loss. A combination of causes of teeth loss was founded in less than $13 \%$ of the subjects for each arch as shown in table $4 \& 5$. This result was statistically significant at $\mathrm{P}>0.001$. 
Table 1. Fisher exact test; Number (n) and percentage (\%) distribution of Kennedy's classes of maxillary arch in relation to age groups.

\begin{tabular}{|c|c|c|c|c|c|c|c|c|c|c|c|}
\hline \multirow{2}{*}{ Age Groups } & \multicolumn{2}{|c|}{ Class I } & \multicolumn{2}{|c|}{ Class II } & \multicolumn{2}{|c|}{ Class III } & \multicolumn{2}{|c|}{ Class IV } & \multicolumn{2}{|c|}{ Total } & \multirow{2}{*}{ P-Value } \\
\hline & $\mathbf{N}$ & $\%$ & $\mathbf{N}$ & $\%$ & $\mathbf{N}$ & $\%$ & $\mathbf{N}$ & $\%$ & $\mathbf{N}$ & $\%$ & \\
\hline $20-29$ & 25 & 23.8 & 24 & 27.0 & 45 & 22.0 & 0.0 & 0.0 & 94 & 16.2 & \\
\hline $30-39$ & 20 & 19.0 & 0.0 & 0.0 & 72 & 35.1 & 0.0 & 0.0 & 92 & 15.9 & \\
\hline $40-49$ & 15 & 14.3 & 45 & 5.6 & 48 & 23.4 & 14 & 23.7 & 122 & 21.1 & $0.000^{*}$ \\
\hline $50-59$ & 15 & 14.3 & 5 & 5.6 & 40 & 19.5 & 45 & 76.3 & 163 & 28.2 & \\
\hline$\geq 60$ & 30 & 28.6 & 15 & 13.9 & 0.0 & 0.0 & 0.0 & 0.0 & 108 & 18.7 & \\
\hline
\end{tabular}

*Significant value

Table 2. Fisher exact test; Number (n) and percentage (\%) distribution of Kennedy's classes of mandibular arch in relation to age groups.

\begin{tabular}{|c|c|c|c|c|c|c|c|c|c|c|c|}
\hline \multirow{2}{*}{ Age Groups } & \multicolumn{2}{|c|}{ Class I } & \multicolumn{2}{|c|}{ Class II } & \multicolumn{2}{|c|}{ Class III } & \multicolumn{2}{|c|}{ Class IV } & \multicolumn{2}{|c|}{ Total } & \multirow{2}{*}{ P-Value } \\
\hline & $\mathbf{N}$ & $\%$ & $\mathbf{N}$ & $\%$ & $\mathbf{N}$ & $\%$ & $\mathbf{N}$ & $\%$ & $\mathbf{N}$ & $\%$ & \\
\hline $20-29$ & 65 & 43.3 & 29 & 28.2 & 0.0 & 0.0 & 0.0 & 0.0 & 94 & 16.2 & \\
\hline $30-39$ & 20 & 13.3 & 19 & 18.4 & 53 & 26.2 & 0.0 & 0.0 & 92 & 15.9 & \\
\hline $40-49$ & 45 & 30.0 & 15 & 14.6 & 62 & 30.7 & 0.0 & 0.0 & 122 & 21.1 & $0.000 *$ \\
\hline $50-59$ & 0.0 & 0.0 & 40 & 38.8 & 87 & 43.1 & 26 & 51.0 & 163 & 28.2 & \\
\hline$\geq 60$ & 20 & 13.3 & 0.0 & 0.0 & 0.0 & 0.0 & 25 & 49.0 & 108 & 18.7 & \\
\hline
\end{tabular}

Table 3. Fisher exact test; Gender number (n) and percentage (\%) distribution of the presence of Kennedy's classes of both arches.

\begin{tabular}{|c|c|c|c|c|c|c|c|c|c|c|c|c|}
\hline \multicolumn{12}{|c|}{ Maxillary Arch } & \multirow{3}{*}{ P-Value } \\
\hline \multirow{2}{*}{ Gender } & & \multicolumn{2}{|l|}{$\mathbf{0 0}$} & \multicolumn{2}{|c|}{ Class I } & \multicolumn{2}{|c|}{ Class II } & \multicolumn{2}{|c|}{ Class III } & \multicolumn{2}{|c|}{ Class IV } & \\
\hline & & $\mathbf{N}$ & $\%$ & $\mathbf{N}$ & $\%$ & $\mathbf{N}$ & $\%$ & $\mathbf{N}$ & $\%$ & $\mathbf{N}$ & $\%$ & \\
\hline & Males & 121 & 100 & 0.0 & 0.0 & 24 & 27.0 & 165 & 80.5 & 29 & 49.2 & \multirow{2}{*}{$0.000^{*}$} \\
\hline & Female & 0.0 & 0.0 & 105 & 100 & 65 & 73.0 & 40 & 19.5 & 30 & 50.8 & \\
\hline \multicolumn{13}{|c|}{ Mandibular Arch } \\
\hline \multirow{2}{*}{ Gender } & Male & 73 & 100 & 40 & 26.7 & 48 & 46.6 & 152 & 75.2 & 26 & 51.0 & \multirow{2}{*}{$0.000^{*}$} \\
\hline & Female & 0.0 & 0.0 & 110 & 73.3 & 55 & 53.4 & 50 & 24.8 & 25 & 49.0 & \\
\hline
\end{tabular}

Table 4. Fisher exact test; Number (n) and percentage (\%) of tooth loss causes with Kennedy's classes of maxillary arch.

\begin{tabular}{llllllllllll}
\hline \multirow{2}{*}{ Causes } & Class I & \multicolumn{3}{c}{ Class II } & \multicolumn{3}{c}{ Class III } & \multicolumn{3}{c}{ Class IV } & \multicolumn{2}{c}{ Total } & P-Value \\
\cline { 2 - 11 } & $\mathbf{N}$ & $\mathbf{\%}$ & $\mathbf{N}$ & $\mathbf{\%}$ & $\mathbf{N}$ & $\mathbf{\%}$ & $\mathbf{N}$ & $\mathbf{\%}$ & $\mathbf{N}$ & $\mathbf{\%}$ \\
\hline Caries & 60 & 57.1 & 44 & 49.4 & 70 & 34.1 & 0.0 & 0.0 & 174 & 30.1 \\
PD & 5 & 4.8 & 30 & 33.7 & 135 & 65.9 & 45 & 76.3 & 215 & 37.1 \\
Trauma & 15 & 14.3 & 0.0 & 0.0 & 0.0 & 0.0 & 14 & 23.7 & 70 & 12.1 & \\
Unknown & 25 & 23.8 & 0.0 & 0.0 & 0.0 & 0.0 & 0.0 & 0.0 & 46 & 7.9 & $0.000^{*}$ \\
C+PD & 0.0 & 0.0 & 15 & 16.9 & 0.0 & 0.0 & 0.0 & 0.0 & 50 & 8.6 & 1.0 \\
C+T & 0.0 & 0.0 & 0.0 & 0.0 & 0.0 & 0.0 & 0.0 & 0.0 & 6 & 3.1 \\
PD+T & 0.0 & 0.0 & 0.0 & 0.0 & 0.0 & 0.0 & 0.0 & 0.0 & 18 & 3.0 \\
\hline
\end{tabular}

PD: Periodontal disease, C: Caries, T: Trauma

Table 5. Fisher exact test; Number (n) and percentage (\%) percentage of tooth loss causes with Kennedy's classes of mandibular arch.

\begin{tabular}{|c|c|c|c|c|c|c|c|c|c|c|c|}
\hline \multirow{2}{*}{ Causes } & \multicolumn{2}{|c|}{ Class I } & \multicolumn{2}{|c|}{ Class II } & \multicolumn{2}{|c|}{ Class III } & \multicolumn{2}{|c|}{ Class IV } & \multicolumn{2}{|c|}{ Total } & \multirow{2}{*}{ P-Value } \\
\hline & $\mathbf{N}$ & $\%$ & $\mathbf{N}$ & $\%$ & $\mathbf{N}$ & $\%$ & $\mathbf{N}$ & $\%$ & $\mathbf{N}$ & $\%$ & \\
\hline Caries & 120 & 80.8 & 48 & 46.6 & 6 & 3.0 & 0.0 & 0.0 & 174 & 30.1 & \\
\hline PD & 10 & 6.7 & 55 & 53.4 & 150 & 74.3 & 0.0 & 0.0 & 215 & 37.1 & \\
\hline Trauma & 0.0 & 0.0 & 0.0 & 0.0 & 46 & 22.8 & 24 & 47.1 & 70 & 12.1 & \\
\hline Unknown & 5 & 3.3 & 0.0 & 0.0 & 0.0 & 0.0 & 27 & 52.9 & 46 & 7.9 & $0.000 *$ \\
\hline $\mathrm{C}+\mathrm{PD}$ & 15 & 10.0 & 0.0 & 0.0 & 0.0 & 0.0 & 0.0 & 0.0 & 50 & 8.6 & \\
\hline $\mathrm{C}+\mathrm{T}$ & 0.0 & 0.0 & 0.0 & 0.0 & 0.0 & 0.0 & 0.0 & 0.0 & 6 & 1.0 & \\
\hline $\mathrm{PD}+\mathrm{T}$ & 0.0 & 0.0 & 0.0 & 0.0 & 0.0 & 0.0 & 0.0 & 0.0 & 18 & 3.1 & \\
\hline
\end{tabular}




\section{Discussion}

The determination of percentage and distribution of partial edentulism and tooth loss among general population are important reasons to assess the impact of preventive dentistry in any society. Furthermore, these data provide information about the prosthodontics treatment needs among the population. This study was carried out among patients attended to outpatient clinic, faculty of dentistry in xyz requiring prosthetic treatment according to their Kennedy classification.

From this finding it is clear that class III has the highest percentage and frequency in maxillary and mandibular arches in all age groups comparing to other classes. This is in agreements with, Sadig and Idowa, [22], AL-Dwairi ZN, [10], NAVEED et al [7], Shinawi LA [23], Eachempati et al [24] and Abdel-Rahman et al [25]. On other hand AL Moaleem et al [26], Niarchou AP et al [27] Pournasrollah et al [28], in their studies they found that class I was the most commonly encountered one in both arches. This could be explained by treatment cost covered by insurance companies for tooth bounded class III, furthermore the preventive program produced by the governments as well as the eating habits.

The results of this study is in agreement with studies conducted by Pellizzer et al [29], ZAIGHAM and MUNEER [30], Shaarma and Stoute [31] and Sapkota et al [32], they concluded in their results that incidences of class III Kennedy classification for maxilla was more frequent.

Anterior teeth are the most retained teeth among general population and the posterior tooth bounded edentulous areas are treated with fixed partial denture. The results of the present study showed that class IV Kennedy classification is the least among all age groups, this is in agreement with the findings of AL Moaleem et al [26], Cha et al [33], ZAIGHAM and MUNEER [30] and AL Judy HJ [34].

In comparison between males and females as in Table 3, males showed more of class III Kennedy classification for both maxillary and mandibular arches. This is in agreement with, AL-Dwairi [10]. While in females, class I Kennedys classification was the highest for both arches, this is in agreement with AL Moaleem et al [26]. But Sapkota [32] showed class III (tooth bounded) is higher among unemployed female group this could be explained by low economic status of the patients, who cannot afford for fixed partial denture treatments. While In comparison between male and females, class IV Kennedy's classification was the least frequent compared to other classes in both arches, this could be explained, by the fact that, patients generally get anterior teeth replaced immediately due to aesthetic reasons.

Retention of the complete dentition throughout life is the main goal of dental health provider. In areas with similarity of geographical, eating habits, social and cultural as well as provided governmental health service. Even though there was no studies conducted to investigate the relationship between Kennedy classification and teeth loss causes. So one of the aimed of this study was to determine the pattern of Kennedy classification and its relationship to teeth loss causes among patients attended to the outpatient's clinics. Table $4 \& 5$ in our results showed that periodontal disease were the most common causes of tooth loss in Kennedy class III followed by class I in maxillary and mandibular arch. This results agreed with some studies conducted in the Saudi Arabia Al Zahrani MS9 [17], Al Sufayyan and Khan [18] and Gossadi et al [19] (Jazan, Saudi Arabia), those concluded that periodontal disease is the most common cause of tooth loss. In a single study conducted by Gossadi et al [19], they concluded a periodontal disease is the major cause of teeth extraction, but caries was found higher in younger age group. Another similar result was founded by ZAIGHAM and MUNEER [30], and Abdel-Rahman et al [33] concluded that direct relation between the age and the tooth loss causes, since the main cause among younger group's patients was dental caries. Then a sudden increase was noticed toward periodontal diseases causes from age 50 years and above. For combined causes of teeth extraction, only few studies were carried out in different regions of Saudi Arabia. They concluded that combined causes of caries and periodontal disease were found in previous studies in private clinics in the capital of kingdom at Riyadh [17-18]. In few cases the cause of tooth loss was trauma, this is in agreement with Abdel-Rahman et al, [25].

The limitation of this study is that, the driven forces of the patient to the clinics is unknown, but most likely the patient relative have connection with the university and the treatment is provided free as compared to dental treatments services is paid treatments in other countries. We recommended for further study with bigger sample size to involve all dental centers in the region. All the obtained results from the present and futures studies will help in the planning of the need of the community regarding prosthesis. Also help in developing preventive programs to avoid losing their teeth.

\section{Conclusions}

Within the limitation of this cross sectional study the following conclusions can be drawn; the highest number of patients was in age group (49-50) in both arches .Class III was the highest among all different age groups followed by class I in group (20-29) and $\geq 60$ of the maxillary arch. While class IV was the highest in group (50-59) in both arches. Class I was the most frequent in female, while class III was in males groups in both arches. Class IV was the lowest in both arches and gender. Periodontal disease was the most common cause of tooth loss in class III in both arches and genders, followed by dental caries. Combinations of causes were founded in less than $13 \%$ of all subjects in each arch. 


\section{Acknowledgment}

This research was supported by a Grant from the Deanship of Scientific Research, FUTURE SCIENTISTS \# III under number (FS3-025), Jazan University, Jazan, Saudi Arabia.

\section{References}

[1] Brodeur JM, Benigeri M, Naccache H, Olivier M \& Payette M: Trends in the Level of Edentulism in Quebec between 1980 and 1993. J Can Dent Asso 1996; 62: 159-166.

[2] Richards W, Ameen J, Coll AM, Higgs G. Reasons for tooth extraction in four general dental practices in South Wales. $\mathrm{Br}$ Dent J 2005; 198: 275-278.

[3] Chestnutt IG, Binnie VI, Taylor MM. Reasons for tooth extraction in Scotland. J Dent 2000; 28: 295-297.

[4] Reich E, Hiller KA. Reasons for tooth extraction in the western states of Germany. Community Dent Oral Epidemiol 1993; 21: 379-383.

[5] Saad El-din SA. The effect of diagnosis and clinical experience on the removable partial denture design. 1998. Master Thesis University of Baghdad.

[6] Bjorn Al, Owall B. Partial edentulism and its prosthetic treatment: A frequency study within a Swedish population. Swed Dent J 1989; 3: 15-25.

[7] NAVEED H, AZIZ MS, HASSAN A, KHAN W, AZAD AA. PATTERNS OF PARTIAL EDENTULISM AMONG ARMED FORCES PERSONNEL REPORTING AT ARMED FORCES INSTITUTE OF DENTISTRY PAKISTAN. Pak Oral dent J 2011; 31: 217-221.

[8] Al-Ansari AA. Prevalence, Severity, and Secular Trends of Dental Caries among Various Saudi Populations: A Literature Review. SJMMS 2014; 2: 142-9.

[9] Esan TA, Olusile AO, Akeredolu PA, Esan AO. Sociodemographic factors and edentulism: the Nigerian experience. BMC Oral Health 2004; 4: 3.

[10] AL- Dwairi ZN: Partial Edentulism and Removable Denture Construction: a Frequency Study in Jordanians. Eur J Prosthodont Restor Dent 2006; 14: 13-17.

[11] Hoover JN, McDermott RE. Edentulousness in patients attending a university dental clinic. J Can Dent Assoc 1989; 55: $139-40$.

[12] Marcus S E, Kaste LM, Brown LJ. Prevalence and demographic correlates of tooth loss among the elderly in the United States. Special Care in Dentistry 1994; 14: 123-127.

[13] Curtis DA, Wagnild GW \& Finzen FC: Incidence of Various Classes of Removable Partial Dentures. J Prosthet Dent 1992; 67: 664-67.

[14] Al-Emran S. REVALENCE OF TOOTH LOSS IN SAUDI ARABIAN SCHOOL CHILDREN: AN EPIDEMIOLOGICAL STUDY OF SAUDI MALE CHILDREN. S Dent J 1990; 2: 137-140.

[15] Al-Shammari KF, Al-Ansari J, Abu Al-Melh M, Al-Khabbaz AK. Reasons for Tooth Extraction in Kuwait. Med PrincPract 2006; 15: 417-422.
[16] Alesia K, Khalil H. Reasons for and patterns relating to the extraction of permanent teeth in a subset of the Saudi population. Clinical, Cosmetic and Investigational Dent 2013; 5: 51-56.

[17] Al-Zahrani MS. Reasons for tooth extraction at three private dental clinics in Saudi Arabia. Egypt Dent J 2009; 55: 21-23.

[18] Al Sufayyan S, Khan N. Reasons for extraction of teeth in paramilitary personnel in Saudi Arabia - a pilot study. J Pak Dent Assoc 2004; 13: 198-203.

[19] Gossadi YI, Al Moaleem MM. REASONS FOR PERMANENT TEETH EXTRACTION IN JIZAN REGION OF SAUDI ARABIA. IOSR-JDMS 2015; 14: 86-89.

[20] Bannasr FH: Prosthetic Status and Needs of Saudi Geriatric Edentulous Patients in Jeddah. Cairo Dent J 2008; 24: 537543.

[21] Mc Caul LK, Jenkins WM, Kay EJ: The reasons for extraction of permanent teeth in Scotland: a 15-year follow-up study. $\mathrm{Br}$ Dent J 2001; 190: 658-62.

[22] Sadig WM \& Idowu AT: Removable Partial Denture Design: A study of a Selected Population in Saudi Arabia. J Contem Dent Pract 2002; 4: 40-53.

[23] Shinawi LA. Partial eduntulism a five year survey on the prevalence and pattern of tooth loss in a sample of patients attending King Abdulaziz University - Faculty of Dentistry.Life Science Journal 2012; 9: 2665-71

[24] Eachempati P, Shenoy VK, Jain N. Prosthetic status and needs of elderly institiutionalized resident in Mangalore: A prospective study. Indian J Dent Reser 2013; 24: 284-88.

[25] Abdel-Rahman HK, Tahir CD, Saleh MM. Incidence of partial edentulism and its relation with age and gender. Zanco J Med Sci 2013; 17: 463-70

[26] AL-Moaleem MM, Al-Sanabani FA, Gebril A, AL-Qahtani MS. DISTRUBITION OF KENNEDY CLASSES AMONG PATIENTS ATTENDED TO COLLEGE OF DENTISTRY, KING KHALID UNIVERSITY. Cairo Dent J 2012; 28: 701706.

[27] Niarchou AP, Ntala PC, Karamanoli EP, Polyzois GL, Frangou MJ. Partial edentulism and removable partial denture design in a dental school population: a survey in Greece. Gerodontology 2011; 28: 177-183.

[28] Pournasrollah A, Negahdari R, Rezaii G, Zarandi A. An Investigation of the Prevalence of Partial. Prosthesis Classification among Patients Swift J Dent Oral Hygiene 2016; 2: 1-6.

[29] Pellizzer EP1, Almeida DA, Falcón-Antenucci RM, Sánchez DM, Zuim PR, Verri FR. Prevalence of removable partial denture user treated at the Aracatuba Dental School - UNESP. - Gerodontology Society and John Wiley \& Sons A/S, Hoboken: Wiley-blackwell 2012, 29: p. 140-144.

[30] ZAIGHAM AM, MUNEER MU. PATTEREN OF PARTIAL EDENTULISM AND ITS ASSOCIATION WITH AGE AND GENDER. Pake Oral \& Dent J 2010; 30: 26063.

[31] Shaama FA, Stoute VA. Mapping of tooth loss profiles and variety of removable partial denture designs fitted to patients in a university dental school clinic in Trinidad. IJMDS 2014; 3: $285-95$. 
[32] Sapkato B, Adhikari B, Upadhaya C. A Study of assessment of Partial Edentulous Patients Based On Kennedys Classification at Dhulikhel Hospital Kathmandu University Hospital. Kathmandu University Medi J 2013; 11: 325-327

[33] Cha P-S, Jeong In-Y, Cho S-A. A clinical study of Kennedy classification and framework design of removable partial denture in Kyungpook National University Hospital. J K Acad Prosthodont 2010; 48: 189-93.

[34] Al Judy HJ. The incidence of frequency of various removable partial edentulism cases. MDJ 2009; 6: 172-77. 